\title{
Numeracy. Open-Access Publishing to Reduce the Cost of Scholarly Journals
}

Todd A. Chavez

USF Libraries, University of South Florida, Tampa FL, tchavez@usf.edu

Follow this and additional works at: https://digitalcommons.usf.edu/numeracy

Part of the Mathematics Commons, and the Science and Mathematics Education Commons

\section{Recommended Citation}

Chavez, Todd A.. "Numeracy. Open-Access Publishing to Reduce the Cost of Scholarly Journals." Numeracy 3, Iss. 1 (2010): Article 8. DOI: http://dx.doi.org/10.5038/1936-4660.3.1.8 


\title{
Numeracy: Open-Access Publishing to Reduce the Cost of Scholarly Journals
}

\begin{abstract}
Each fiscal year, as academic librarians throughout the United States prepare materials budgets, a national "groan" ensues. Regardless of their format (i.e. print or digital), serial subscription costs are escalating, in the process impacting the role of the library in advancing scholarly communication. This paper examines some of the economic issues concerning open-access (OA) journal publishing. The importance of quantitative literacy is suggested for librarians and academics seeking a better understanding of alternatives to traditional journal subscription models and to anyone considering ventures into OA publishing. Quantitative literacy is essential for managing alternatives to the rising cost of scholarly communication.

The OA movement is gaining traction at the national level, following mandates from the National Institutes of Health and at some large research universities that host institutional repositories. Science faculty has been engaged in scholarly communication OA models since the 1970s. More broadly, discussions in academe have focused on $\mathrm{OA}$ and its impact on peer review, promotion and tenure, intellectual property rights, and measures of institutional and faculty productivity. Studies concerning the OA movement's economics are most commonly reported in academic librarianship literature, a trend that may serve as a barrier to a broader understanding of OA's role in scholarly communication. This paper provides background information on the crisis in serials costs and suggests that metrics favor OA models publishing models. A concluding proposal concerning library-funded OA serial collections is offered as a catalyst for further discussions.
\end{abstract}

\section{Keywords}

Open-access publishing, librarianship, quantitative literacy, Economics of publishing

\section{Creative Commons License}

\section{c) (7) (8)}

This work is licensed under a Creative Commons Attribution-Noncommercial 4.0 License 


\section{Introduction}

The rising cost of scholarly communications increases the cost of library resources, which in turn reduces teaching effectiveness, thwarts research, and limits community access to scholarship. In particular, rising serial costs restrict the growth of library collections in non-serial formats (e.g., books, databases, unique print collections). The damage to library resources is exacerbated by the recent global economic recession.

The Association of Research Libraries (ARL 2006) reports the trends as percentage changes over the 20-year period from 1986 to 2006. During that period, ARL member libraries experienced a $321 \%$ increase in serial expenditures coinciding with an average increase in unit cost of $180 \%$. The additional expenditures generated only a $51 \%$ increase in the number of serial titles purchased. For the same period, monograph expenditures increased $82 \%$, although the number of monographs purchased rose a mere $1 \%$. Unsurprisingly given these trends, acquisitions per student have declined $19 \%$ over the past eight years.

These trends reverberate throughout the publishing community: declining acquisitions accompany reduced demand for academic monographs. Average printings in 2006 numbered 200-400 copies, as compared to 1,500 copies in 1996. Serials are not immune. Journal cancellations are increasing even as scholarly communication levels worldwide have doubled since the mid-1980s according to the Association of College and Research Libraries (ACRL 2006).

Commercial electronic journal package vendors are operating outside of corrective market forces (e.g., using non-standard pricing structures) thereby increasing profit margins. The apparent strategy includes accumulating everlarger content "bundles" drawn from smaller publishers and scholarly associations that are subsequently forced out of the market. This practice reduces avenues for scholarly communication, disproportionally marginalizes non-scientific literature in the marketplace, and limits its availability according to the Association of Learned and Professional Society Publishers (ALPSP 2008). How these changes in publisher behavior will finally impact these institutions is not yet certain. Many scholarly associations consider journals important benefits to their members, for example, so ceasing publication or converting to a commercial supplier may impact the association's bottom line (Willinsky 2006).

As the effects of the current economic crisis unfolded, libraries faced with declining materials budgets and reduced endowment funds took firm stands with publishers to mitigate potential cancellations. Some negotiators included hardship clauses in renewals to ensure that the institution could legally escape a contract if 
funds were reduced further. Organizations such as the ARL and the ACRL put publishers on notice: hold the line on costs or lose subscribers.

Each year, the Library Journal's "Periodical Price Survey" describes trends in journal pricing and suggests future developments. The latest survey (Van Orsdel and Born 2009) was grim at best. On average, libraries canceled 177 journal titles per library in 2008. Cost increases in journals grouped by Library of Congress Subject during 2008-2009 ranged from 5\% (Geography and Physics) to $10 \%$ for titles in Law and Psychology. ${ }^{1}$ Librarians' concerns during the 2010 renewal cycle will likely deepen if Van Orsdel's and Born's projections are realized. They suggest that journal costs in the arts and humanities may rise by $7 \%$, while those in the social sciences and sciences will rise by $8.3 \%$ and $7.5 \%$, respectively. Given average annual subscription prices for science journals at between \$1,089 (Agriculture) and \$3,690 (Chemistry), this news is not encouraging.

\section{Rising Serial Costs and the CPI}

To see the run-away increases in serial subscription prices, consider its trajectory compared to the annual percentage change in the Consumer Price Index (CPI), as reported by the U.S. Department of Labor. According to the ACRL, North American research libraries experienced annual subscription cost increases ranging from $6 \%$ to $12 \%$ and spent $227 \%$ more for their journal collections in 2002 than in 1986. The CPI increased 57\% during the same period (ACRL 2006). For the more recent period, 2005-2009, see Table 1, which lists the percentage changes by Library of Congress subject. The contrast between the relative rate of change of subscription prices and the CPI is stunning (last rows of the table).

\section{Open-Access Journals as a Solution}

Van Orsdel and Born (2009) conclude their report with two recommendations to library managers: (1) plan for as high as a 7-9\% increase in periodical prices, and (2) lobby for open-access (OA) mandates in universities and government funding agencies. The rest of this paper discusses one university library's reaction to this second recommendation.

${ }^{1}$ A $30 \%$ increase for recreation titles was excluded, as different market forces influenced this area. 
Table 1

Serial Subscription Costs and the CPI

\begin{tabular}{|c|c|c|c|c|}
\hline \multirow[b]{2}{*}{ Library of Congress Subject } & \multicolumn{4}{|c|}{ Percent Change } \\
\hline & $2005 / 06$ & $2006 / 07$ & 2007/08 & $2008 / 09$ \\
\hline Agriculture & 7 & 8 & 7 & 7 \\
\hline Anthropology & 5 & 8 & 12 & 9 \\
\hline Art \& Architecture & 8 & 7 & 10 & 6 \\
\hline Astronomy & 10 & 4 & 8 & 9 \\
\hline Biology & 10 & 9 & 7 & 7 \\
\hline Botany & 8 & 8 & 8 & 8 \\
\hline Business \& Economics & 6 & 7 & 8 & 7 \\
\hline Chemistry & 8 & 7 & 7 & 7 \\
\hline Education & 9 & 11 & 10 & 8 \\
\hline Engineering & 7 & 7 & 7 & 9 \\
\hline Food Science & 8 & 5 & 8 & 9 \\
\hline General Science & 6 & 9 & 7 & 9 \\
\hline General Works & 5 & 9 & 8 & 5 \\
\hline Geography & 6 & 9 & 9 & 5 \\
\hline Geology & 5 & 8 & 9 & 8 \\
\hline Health Sciences & 9 & 9 & 9 & 8 \\
\hline History & 8 & 9 & 12 & 9 \\
\hline Language \& Literature & 6 & 8 & 11 & 5 \\
\hline Law & 10 & 11 & 7 & 10 \\
\hline Library \& Information Science & 5 & 7 & 8 & 6 \\
\hline Math \& Computer Science & 5 & 7 & 7 & 6 \\
\hline Military \& Naval Science & 19 & 3 & -9 & 7 \\
\hline Music & 4 & 9 & 16 & 6 \\
\hline Philosophy \& Religion & 7 & 10 & 10 & 6 \\
\hline Physics & 6 & 9 & 6 & 5 \\
\hline Political Science & 10 & 11 & 11 & 9 \\
\hline Psychology & 8 & 8 & 9 & 10 \\
\hline Recreation & 7 & 6 & 15 & 30 \\
\hline Sociology & 8 & 10 & 9 & 9 \\
\hline Technology & 7 & 7 & 8 & 7 \\
\hline Zoology & 8 & 10 & 12 & 9 \\
\hline Median Change & 7 & 8 & 8 & 8 \\
\hline Average Change & 7.58 & 8.06 & 8.58 & 8.22 \\
\hline CPI & 3.4 & 2.5 & 4.1 & 0.1 \\
\hline
\end{tabular}

Sources: Adapted from Van Orsdel and Born 2009; CPI data from U.S. Bureau of Labor Statistics 2009. 


\section{Open-Access Journal Publishing}

The term open access is defined by the Library of Congress as,

A publication model wherein neither readers nor a reader's institution are charged for access to articles or other resources. Users are free to read, download, copy, distribute, print, search, or link to the full texts of these articles. The only constraint on reproduction and distribution, and the only role for copyright ... should be to give authors control over the integrity of their work and the right to be properly acknowledged and cited. ${ }^{2}$

Although information in the open-access (OA) environment is cost-free to individual and institutional consumers, OA titles are not without costs for the publisher.

As of September 2009, the Directory of Open Access Journals (DOAJ), an international collaborative that limits its coverage to scholarly, peer-reviewed OA journals, lists 4,358 journal titles encompassing 313,973 articles in 17 broad subject/discipline areas. The DOAJ defines open-access journals as "journals that use a funding model that does not charge readers or their institutions for access."

\section{Open-Access Journal Publishing Models}

Business models defining OA publishing options abound. ${ }^{3}$ Willinsky (2006) identifies 10 "flavors" of OA based on financing and access protocols.

Walters and Wilder (2007) provide a concise overview of three pricing models: conventional, Public Library of Science (PLoS) $)^{4}$ open access, and equalrevenue open access. The conventional model is the most common of the three. Its revenues are derived from subscriptions, page charges, and submission fees (Walters and Wilder 2007, 620). The PLoS OA model relies on the author or institution to provide article publication fees to offset the cost required to make a traditionally subscription-restricted publication available without charge to the reader. The costs associated with this approach can be drawn directly from the institution's or author's budget or included in grant proposals. In the equal-

\footnotetext{
${ }^{2}$ The "Budapest Open Access Initiative" [http://www.soros.org/openaccess (accessed Dec. 4, 2009)] and the "Bethesda Statement" [http://www.biomedcentral.com/openaccess/bethesda/ (accessed Dec. 4, 2009)] Web sites provide deeper definitions of the open-access concept.

${ }^{3}$ Crow and Goldstein (2003) provide a practical template for crafting a business plan for openaccess publishing in light of the Open Society Institute's preferred model. Lamb (2004) and McCabe (2004) provide general overviews of open-access publishing models and their economic implications. Willinsky (2003) discusses open-access model viability as it relates to scholarly associations.

${ }^{4}$ http://www.plos.org/oa/index.html (accessed Dec. 4, 2009).
} 
revenue OA example, publishers and subscribers equally share the costs associated with publication.

These three models share a spectrum with numerous hybrids (e.g., Cockerill 2009; Earl 2008; Pinfield 2006). Publishers such as Blackwell, Oxford University Press, and Springer support various hybridized strategies in which they sustain minor reductions in their earnings, and the creators or their institutions gain flexibility in disseminating their intellectual content.

\section{Costs of Open-Access Publishing}

The decision to engage in OA journal publishing is in part a deliberate response to the increasing cost of scholarly communication, including technology, distribution, materials, and reacquisition of copyright permissions. Prestigious research institutions, including Yale and Cornell, have responded to these increases with a shift to OA publishing models. In some instances, large research libraries have not renewed subscriptions to protest rising costs (Van Orsdel and Born 2008). Although this crisis of rising costs is present in all disciplines, the most acute examples are found in the scientific, technical, and medical domains.

In 2000, the science, technical and medical publishing market was valued at $\$ 9.5$ billion, including $\$ 1.6$ billion in aggregator content $-68 \%$ generated by commercial vendors and 32\% contributed by non-profit entities (Johnson 2003). This division is important when considering the nature and values of commercial and scholarly publishing "cultures." At the risk of over-generalizing, the culture of scholarly publishing aims to increase content awareness, focus efforts on publication output, and reward publication prestige through tenure and promotion. By contrast, the culture of commercial publishing maximizes product value, focuses efforts on controlling content and access, and rewards increased profit (Johnson 2002). These are largely incompatible views of the publishing endeavor.

Actual publication costs depend on a variety of considerations, ranging from the model adopted, to the number of articles published per issue, to archival strategies. Despite this variability, it may be useful to examine three published cost estimates, ranging from an extremely low (and optimistic) cost structure to one that seems unduly excessive.

The first example is the cost-structure model used by the University of South Florida Libraries to publish this journal and two additional titles in geology and globalization. Our venture limits equipment and facility expenditures by contracting with an established journal management system provided by Bepress, a strategy that makes the project less expensive and more attractive to administrators concerned with long-term sustainability. As in any project for which little or no infrastructure exists, salary costs are typically the most significant budget element. This model addresses that issue by absorbing the funding of the editors in their existing job assignments. Infrastructure costs, 
however, are not as easily absorbed. As the number of supported titles grows, it likely will become necessary to allocate specific staff resources. At this time, the journals' management system and hosting costs are "fixed," but subsequent years will require additional funds. The actual budget for a single title is summarized in Table 2.

Table 2

Summary of Actual Three-Year Costs for One Title in the University of South Florida Libraries' Open-Access Journal Collection

\begin{tabular}{lccc}
\hline Cost Areas & $\begin{array}{c}\text { Year } \mathbf{1} \\
\mathbf{( \$ )}\end{array}$ & $\begin{array}{c}\text { Year 2 } \\
\mathbf{( \$ )}\end{array}$ & $\begin{array}{c}\text { Year 3 } \\
\mathbf{( \$ )}\end{array}$ \\
\hline One-Time Journal Start-Up & 2,500 & NA & NA \\
Journal Management System & 5,000 & 5,000 & 5,000 \\
Archiving & 400 & 400 & 400 \\
\hline TOTAL COSTS & $\mathbf{7 , 9 0 0}$ & $\mathbf{5 , 4 0 0}$ & $\mathbf{5 , 4 0 0}$ \\
\hline
\end{tabular}

In the USF Libraries case, the number of articles per issue for the three titles in the collection averaged 4, 7, and 7 over the past two years. The cost per article for Numeracy (based upon an average of four articles per issue) totaled $\$ 1,975$ in year one and $\$ 1,350$ in each successive year. For the other journals, the cost per article was $\$ 1,128$ in year one and $\$ 771$ thereafter. It is important to note that the systems used are scalable and thus can sustain significant growth in article production with no change in fixed costs per issue. A more comprehensive survey of library-supported OA projects would suggest a variety of cost structures; I do not claim that the USF case is representative.

The second example is illustrated by Table 3, which summarizes production costs (excluding printing and fulfillment) for an anonymous society journal variously published using both subscription-based and OA models (Johnson 2005). The costs itemized in the table represent the most basic publication functions/cost centers needed to release an electronic journal to the reader via the Internet. These functions are subsumed under the "Journal Management System" line item in the USF Libraries example (Table 2). Composition and platform costs are compared in Table 3 because they represent analogous functions performed either by the publisher's staff or by the software and journal management system. Note that the platform, PDF creation, author alterations, XML conversion, and overhead costs in this example are included in the journal management costs in the USF Libraries example. The number of articles per issue was not reported in this example (Johnson 2005), so direct comparison with the USF Libraries example is not possible. 
Table 3

Production Costs for an Anonymous Society Journal

\begin{tabular}{lr}
\hline \multicolumn{2}{c}{ Subscription Journal } \\
\cline { 2 - 2 } Composition & \multicolumn{1}{c}{ Cost $(\$)$} \\
PDF Creation & 102,000 \\
Archiving & 3,600 \\
Staff & 1,300 \\
Author Alterations & 339,500 \\
XML Conversion & 11,600 \\
Overhead & 20,000 \\
TOTAL & 252,200 \\
\hline
\end{tabular}

\begin{tabular}{lc}
\multicolumn{2}{c}{ Open-Access Journal } \\
\cline { 2 - 2 } Platform & Cost $(\$)$ \\
PDF Creation & 5,000 \\
Archiving & 3,600 \\
Staff & 1,300 \\
Author Alterations & 104,000 \\
XML Conversion & NA \\
Overhead & NA \\
TOTAL & 92,400 \\
\hline
\end{tabular}

Source: Johnson (2005).

Table 3 suggests the potential economies generated by adopting an OA model for journal publishing and reveals some of the sources of escalating commercial subscription costs passed on to the subscriber.

A third example (Morris 2005) considers that the "real" costs must take the entire process into account: research, writing, publishing, acquiring, reading, and preserving the work. In total, Morris (2005) estimates that the cost of scholarly communication surrounding one research article ranges from $\$ 97,140$ to $\$ 99,265$ (Table 4).

Table 4.

Summary of Morris' "True Cost" of Scholarly Communication

\begin{tabular}{lll}
\hline Pre-Publication & Research & $\$ 50,000$ \\
& Writing & $\$ 6,700$ \\
Publication & Refereeing & $\$ 5,640$ \\
& Publishing & $\$ 2,250-4,375$ \\
Post-Publication & Acquisition & $\$ 2,820$ \\
& Library Costs & $\$ 4,230$ \\
& Preservation & Unknown \\
& Reading & $\$ 30,600$ \\
\hline TOTAL & & $\$ 97,140-99,265$ \\
\hline
\end{tabular}

Source: Morris 2005, 122

This last estimate is difficult to compare directly to the preceding examples because so many of the activities (e.g., research and writing) go on regardless of the model used to acquire and publish journals. Additionally, Morris's accounting of the cost of "reading" - costs she ascribes to faculty and student consumption of the published content-is difficult to accept. Her model considers the "value" that authors (and libraries) simply hand over at no cost to commercial publishers 
who subsequently sell that intellectual energy back to the authors' institution via subscription fees.

\section{The State of Open-Access Publishing in 2009}

Van Orsdel and Born (2005) found that the number of titles listed in the DOAJ had doubled during the period 2004/05, with substantial increases in peerreviewed titles in many disciplines. They reported on a study that revealed that OA journals tracked for impact factors were increasing in importance overall and concluded from a literature review that consumption of OA content will ultimately exceed "toll-access" in both citations and downloads. Results of their 2009 survey suggest that this positive trend is gaining momentum (Van Orsdel and Born 2009).

Gradual pressure is building on scholars' and researchers' ability to communicate with one another and for consumers of their intellectual energies to access the information. In 2003, Congressman Martin Sabo introduced a bill to make all research funded by the federal government exempt from copyright protections, thereby giving a significant boost to OA publishing models (The Scientist 2003). Unfortunately, the controversy generated by copyright exemption overshadowed the bill's very real potential to promote OA publishing, and publishers and prominent representatives of the research community, including the Association of American Universities (AAU), rose in opposition.

The National Institutes of Health (NIH) Public Access Policy (2008) serves as a prominent example of a mandate to expand $\mathrm{OA}$ publishing that also preserves copyright protections:

The Director of the National Institutes of Health shall require that all investigators funded by the NIH submit or have submitted for them to the National Library of Medicine's PubMed Central an electronic version of their final, peer-reviewed manuscripts upon acceptance for publication, to be made publicly available no later than 12 months after the official date of publication: Provided, That the NIH shall implement the public access policy in a manner consistent with copyright law. ${ }^{5}$

One year after this policy's implementation, the NIH reports success and little dissent on the part of researchers. But resistance from the publishing community continues. The current strategy, led by the Association of American Publishers, seeks to enact the "Fair Copyright in Research Works Act," legislation that would overturn the NIH policy and prevent future government-mandated OA policies.

Other entities have pressed for OA alternatives to traditional publishing. In 2009, Harvard University faculty, the Association of American Universities, the

\footnotetext{
${ }^{5}$ http://publicaccess.nih.gov/policy.htm (accessed Dec. 8, 2009)
} 
Coalition for Networked Information, and the National Association of State Universities and Land Grant Colleges independently supported OA initiatives on local and national levels. In the United Kingdom, a study commissioned by the Joint Information Systems Committee concluded that British universities stood to save over $£ 80$ million annually by moving away from subscription dependence and investing in OA publishing (Houghton et al. 2009).

\section{What Do Authors Think of Open Access?}

Authors express a variety of opinions about OA publication of their works, generalized by the following statement: authors support OA publishing models so long as their intellectual property rights are protected, rigorous peer review is maintained, and authors' costs are minimal or non-existent (Nicholas et al. 2006).

Concerns over sustaining peer review recur in the surveys consulted for this paper (Davies and Greenwood 2004; Nicholas et al. 2006). Authors express the importance of avoiding readers' assumptions that "free = cheap" — conflating OA content with lower-quality information sources. Examples such as the PLoS and Biomed Central $^{6}$ have reduced this concern by successfully coupling rigorous peer review with rapid article dissemination. Nicholas et al. (2006) report that the concerns with the peer-review process have diminished from $34 \%$ to $19 \%$ in their survey respondents. Partly in response to these concerns, as well as notable recent failures in the traditional quality-assurance processes, Pöschl (2004) proposes a provocative alternative to traditional peer review: a two-stage process whereby authors submit their work to a "scientific discussion forum" in which peers and the public comment on and review the work prior to submission for final publication.

Authors otherwise committed to open access are also concerned with the impact of OA publications on promotion and tenure (Björk 2004). These concerns are inextricably linked to peer-review rigor and misperceptions that OA journals are free and ephemeral and therefore of less quality and endurance than publications restricted by subscription access.

A related issue concerns the number of OA journals given Impact Factors by the ISI. In a study of the ISI databases, McVeigh (2004) reported that 55\% of the journals indexed by ISI permitted self-archiving. Using three indexes of OA publications, she determined that ISI indexed 192 and 239 of the indexed publications in 2002 and 2004, respectively. The 2004 list accounted for approximately $20 \%$ of the 1,190 titles indexed in the OA repositories. Of the 239 titles indexed in 2004 (primarily in journals drawn from medicine and the life sciences), 197 had sufficient data for determining an Impact Factor. Increasing

\footnotetext{
${ }^{6}$ http://www.biomedcentral.com/ (accessed Dec. 4, 2009).
} 
ISI's and other associated resources' (e.g., SCOPUS) coverage of OA journals may form the basis for a resolution to these concerns.

Finally, as a colleague recently wrote in an email, "Some of us like bricks and mortar, good journals associated with comfortable reading chairs, and, simply, the look, feel, and smell of good libraries." I empathize with his sentiments and assert that his comments illustrate how this issue is more complicated for faculty than the economic metrics suggest.

\section{Academic Libraries and Open-Access Publishing}

Research libraries are "becoming more deeply engaged in the creation and dissemination of knowledge and are becoming essential collaborators with the other stakeholders in these activities" (Lougee 2002, p. 3). A natural extension of this engagement is the research library's emerging role as publisher. In this scenario, scholars' intellectual property, supported by the library, remains within the academy and is available for dissemination via an OA model.

Support for this concept is strongly reflected in the 2005 Cornell University faculty's "Resolution on Open Access and Scholarly Communication" (Cornell University Library 2005), which states in part:

The Senate calls upon all faculty to become familiar with the pricing policies of journals in their specialty.

The Senate strongly urges tenured faculty to cease supporting publishers who engage in exorbitant pricing, by not submitting papers to, or refereeing for, the journals sold by those publishers, and by resigning from their editorial boards if more reasonable pricing policies are not forthcoming.

Reaffirming and broadening the proposals discussed during its meeting of December 17, 2003, the Senate strongly urges the University Library to negotiate vigorously with publishers who engage in exorbitant pricing and to reduce serial acquisitions from these publishers based on a reasonable measure of those subscriptions' relative importance to the collection, taking into account any particular needs of scholars in certain disciplinary areas.

The Senate strongly encourages all faculty, and especially tenured faculty, to consider publishing in open access, rather than restricted access, journals or in reasonably priced journals that make their contents openly accessible shortly after publication.

The idea of academic libraries as publishers aligns with the strategic plan of the ARL and practices of ARL member libraries. Strategic Direction 1 of the 2005-09 plan states (ARL 2005):

ARL will be a leader in the development of effective, extensible, sustainable, and economically viable models of scholarly communication that provide barrier-free 
access to quality information in support of teaching, learning, research, and service to the community.

According to a recent survey of ARL libraries ( 80 respondents), $43 \%$ engaged in publishing activities, $21 \%$ planned to begin, and $36 \%$ did publish or plan to publish (Hahn 2008). Barriers to OA publishing within the library community can benefit from the ARL experience.

Thomas (2006) provides another encouraging example of the academic libraries' potential to advance scholarly communication broadly through her discussion of Cornell University Library's successful initiatives with Project Euclid $^{7}$ (OA journals in Mathematics and Statistics), $\operatorname{arXiv}^{8}$ (a preprint repository for high-energy physics previously supported by the NSF), and $\mathrm{DPubS}^{9}$ (an opensource content management application facilitating institutional repository management). Academic libraries can bring to bear skills in diverse arenas, including digital initiative project management, content acquisition and organization, license negotiation, and preservation. But Thomas' Cornell example has not yet permeated the entire research library community.

\section{A Radical Solution?}

I believe the debate over OA publishing is similar to the battle over health care reform. It is a complex issue with significant economic impact. The consequences of failing to act are arguably significant. In the case of OA publishing, maintaining the status quo, I believe, predetermines a decrease in access to quality information.

In conclusion, I propose a radical solution to the problems of escalating costs and decreasing access. In 2006, the median expenditure for serials collections among the 113 ARL members totaled $\$ 6,289,768$, and the median number of titles acquired for this expenditure was 40,607 or $\$ 154.89$ per title. If each of the 113 members took responsibility for an equal number of titles and published them using an OA model that generated no costs for readers or "subscribing" institutions, each library would "own" and manage 359 titles. If one assumes that the USF Libraries' experience can be replicated, the base cost for these 359 titles would total $\$ 1,938,600$. Alternatively, if we accept the costs outlined for a commercial publisher in Table 3 and add staff costs of $46 \%$ to this total, the cost of publishing 359 titles using an OA model, including staff support, would approximate $\$ 2,830,356$. In comparison, in 2006-07, the USF Libraries expended $\$ 4,214,488$ for their 31,685 serial titles.

${ }^{7} \mathrm{http} / / /$ projecteuclid.org/ (accessed Dec. 4, 2009).

8 http://arxiv.org/ (accessed Dec. 4, 2009).

9 http://dpubs.org/ (accessed Dec. 4, 2009). 
Libraries can afford to lead OA publishing efforts. If we partner with faculty from across the academy to resolve some of the other concerns discussed above, the economic challenges can be overcome and OA publishing can be made a reality.

\section{Acknowledgments}

I want to thank USF Professor Len Vacher and his colleagues from the National Numeracy Network for supporting the concept that the USF Libraries sponsor the NNN's publication of Numeracy and exemplifying what I mean by partnering with faculty across the academy. In that vein, I also want to thank USF Professor Bogdan Onac for placing the open-access journal that he edits-Studia Universitatis Babes-Bolyai, Geologia - with the USF Libraries. Comments from Dr. Vacher and the anonymous reviewers were very helpful and strengthened this paper.

\section{References}

American Mathematical Society. 2007. Journal price survey (1994-2004). http://www.ams.org/membership/journal-survey.html (accessed Feb. 7, 2007).

Association of College \& Research Libraries. American Library Association (ACRL). 2006. Journal pricing. Scholarly Communication Toolkit. http://www.library.cornell.edu/scholarlycomm/resolution.html (accessed Feb. 7, 2007).

Association of Learned and Professional Society Publishers (ALPSP). 2008. Academic journal publishers' policies and practices in online publishing: Third survey. Scholarly Publishing Practice 3(2008): 1-116.

Association of Research Libraries (ARL). 2005. ARL Strategic Plan, 2005-2009. About ARL: Governance. http://www.arl.org/arl/governance/stratplan.shtml (accessed Feb. 2, 2007).

Association of Research Libraries (ARL). 2006. ARL statistics, 2005-06. Washington, D. C.: Association of Research Libraries.

Björk, Bo-Christer. 2004. Open access to scientific publications-An analysis of the barriers to change. Information Research 9(2): 1-14.

Cockerill, Matthew. 2009. Establishing a central open access fund. OCLC Systems \& Services 25(1): 43-46. http://dx.doi.org/10.1108/10650750910931913

Cornell University Library. 2005. Cornell University Faculty Senate endorses resolution on open access and scholarly communication. http://www.library.cornell.edu/scholarlycomm/resolution.html (accessed Feb. 7, 2007). 
Crow, Raym, and Howard Goldstein. 2003. Model business plan: A supplemental guide for open access journal developers \& publishers.” 2003. Open Society Institute. http://www.soros.org/openaccess/oajguides/oaj_supplement_0703.pdf (accessed Dec. 9 2009).

Davies, J. Eric, and Helen Greenwood. 2004. Scholarly communication trends-Voices from the vortex: A summary of specialist opinion.” Learned Publishing 17(2): 157-67. http://dx.doi.org/10.1087/095315104322958544

Earl, Peter E. 2008. Heterodox economics and the future of academic publishing. On the Horizon 16(4): 205-13. http://dx.doi.org/10.1108/10748120810912538

EBSCO. 2007. Serials prices 2005-2007 with projections for 2008. EBSCO Subscription Services. http://www.ebsco.com/home/printsubs/priceproj.asp (accessed Aug. 12, 2008).

Hahn, Karla. 2008. Research library publishing services: New options for university publishing and new roles for libraries. ARL 258 (June 2008): 6-9.

Houghton, John W., Bruce Rasmussen, Peter Sheehan, Charles Oppenheim, Anne Morris, Claire Creaser, Helen Greenwood, Mark Summers and Adrian Gourlay. 2009. Economic implications of alternative scholarly publishing models exploring the costs and benefits. Report to the UK Joint Information Systems Committee. http://www.jisc.ac.uk/media/documents/publications/rpteconomicoapublishing.pdf (accessed Dec. 9, 2009).

Johnson, Richard K. 2002. Igniting change in scholarly communication. Cowles Library National Advisory Board Guest Lecture. Drake University, Des Moines, IA. Oct. 4.

- 2003. Open access: Unlocking the value of research. Meeting of the Scholarly Publishing \& Academic Resource Coalition, Ohio State University. Jan. 15.

- 2005. Market remedies: The role of open access publishing. Symposium on Antitrust Issues in Scholarly \& Legal Publishing. Information Access Alliance \& American Antitrust Institute, Washington, DC. Feb. 11.

Kean, Gene. 2007. 19 ${ }^{\text {th }}$ annual study of journal prices for scientific and medical society journals. Journal Publishing 2007(1): 1-15.

Kyrillidou, Martha. 2000. Journal costs: Current trends and future scenarios for 2020. ARL 210 (June): 4.

Lamb, Christine. 2004. Open access publishing models: Opportunity or threat to scholarly and academic publishers?" Learned Publishing 17(2): 143-50. http://dx.doi.org/10.1087/095315104322958526

Lougee, Wendy Pradt. 2002. Diffuse libraries: Emergent roles for the research library in the digital age. Washington, DC: Council on Library and Information Resources.

McCabe, Mark, and Christopher M. Snyder. 2004. The economics of open-Access journals. Working Papers 04-18, NET Institute.

McVeigh, Marie E. 2004. Open access journals in the ISI citation databases: Analysis of impact factors and citation patterns. Thomson Scientific. http://science.thomsonreuters.com/m/pdfs/openaccesscitations2.pdf (accessed Jan. 12, 2009).

Morris, Sally. 2005. The true costs of scholarly Journal publishing. Learned Publishing 18(2): 115-26. http://dx.doi.org/10.1087/0953151053584975 
Nicholas, David, Paul Huntington, and Hamid R. Jamali. 2007. The impact of open access publishing (and other initiatives) on use and users of digital scholarly journals. Learned Publishing 20(1): 11-15. http://dx.doi.org/10.1087/ $\underline{095315107779490599}$

Nicholas, David, Hamid R. Jamali, and Ian Rowlands. 2006. On the tips of their tongues: Authors and their views on scholarly publishing. Learned Publishing 19(3): 193-203. http://dx.doi.org/10.1087/095315106777877494

Pinfield, Stephen. 2006. A wel(1)come development: Research funders and open access." Learned Publishing 19(3): 219-25. http://dx.doi.org/10.1087/095315106777877548

Pöschl, Ulrich. 2004. Interactive journal concept for improved scientific publishing and quality assurance. Learned Publishing 17(2): 105-13.

Primary Research Group. 2009. Survey of academic \& research library journal purchasing practices. New York: Primary Research Group.

The Scientist. 2003. Sabo bill sparks copyright controversy. 17(16): A2-A3.

Thomas, Sarah E. 2006. Publishing solutions for contemporary scholars: The library as innovator and partner. Library Hi Tech 24(4): 563-73. http://dx.doi.org/10.1108/ $\underline{07378830610715428}$

U.S. Bureau of Labor Statistics. Department of Labor. 2009. Consumer price index: All urban consumers (CPI-U): U.S. city average. ftp://ftp.bls.gov/pub/special.requests/cpi/cpiai.txt (accessed June 18, 2009).

Van Orsdel, Lee C., and Kathleen Born. 2005. Choosing sides-Periodicals price survey 2005. Library Journal 130(7): 43-48.

- 2008. Periodicals price survey 2008: Embracing openness. Library Journal, April 15). http://www.libraryjournal.com/article/CA6547086.html (accessed Nov. 11, 2008).

- 2009. Periodicals price survey 2009: Reality bites.” Library Journal 134(7), April 15). http://www.libraryjournal.com/article/CA6651248.html (accessed June19, 2009).

Walters, William H., and Esther Isabelle Wilder. 2007. The cost implications of openaccess publishing in the life sciences. BioScience 57(7): 619-625. http://dx.doi.org/ $\underline{10.1641 / \mathrm{B} 570709}$

White, Sonya, and Claire Creaser. 2004. Scholarly journal prices: Selected trends and comparisons. LISU Occasional Paper 34. Leicestershire: Loughborough University. 2007. Trends in scholarly journal prices, 2000-2006. LISU Occasional Paper 37. Leicestershire: Loughborough University.

Willinsky, John. 2006. The access principle: The case for open access to research and scholarship. Cambridge, MA: MIT Press.

. 2003. Scholarly associations and the economic viability of open access publishing. Journal of Digital Information 4(2). http://works.bepress.com/ir research/13 (accessed Dec. 12, 2008). 